\title{
EFEKTIVITAS PENGGUNAAN MEDIA VIDEO LEARNING MULTIMEDIA (VLM) TERHADAP PENGETAHUAN INFEKSI MENULAR SEKSUAL (IMS) (STUDI PADA WARIA DI KOTA MAKASSAR)
}

\section{1| Andi Asrina, 2| R. Sudirman}

Email : andi.asrina@umi.ac.id, r.sudirman029@gmail.com

ABSTRACT
One cause of transmission of STIs is the knowledge and attitudes of transvestites about risk
behavior. Minimal knowledge about sexually transmitted diseases does not need to use a
condom when transacting at the request of a sexy partner. In Makassar City, there are
many transgender groups and actively engaging in sexual relations that cause STIs which
are the entry point for HIV / AIDS. The disease is increasing every year, sure in 2015 there
were 665 new HIV positive, in 2016 it increased to 773, then in 2017 there were 1038 new
HIV and until June 2018 there were 354 people who bought new HIV. The purpose of this
study is to determine the effectiveness of the use of video media and leaflets on the
knowledge and attitudes of transgender people about sexually transmitted infections (STI)
in Makassar City. The population was transvestites in the Mamajang Region as many as 84
people, the sample was determined by purposive sampling, so that 30 transvestites were
obtained. Based on the research results obtained by respondents the lowest was 17 years
(3.3\%) and those aged 24 years (13.3\%)) which produces age. Based on the pretest and
posttest, there was no significant effect between the provision of VLM on the knowledge of
Transvestites with a value of 0.105, as well as the attitude of Transgender with a value of $p$
o.125. This study concludes that there is no difference between VLM and knowledge and
attitudes about STIs.

ARTICLE INFO

\begin{tabular}{l} 
ARTICLE INFO \\
\hline Keywords: \\
Sexual transmitted infections; \\
Audio visual; Knowledge; Attitude
\end{tabular}

Pendahuluan

Infeksi Menular Seksual (IMS) masih merupakan masalah kesehatan yang cukup serius di dunia, termasuk di Indonesia karena penyakit ini terus mengalami peningkatan setiap tahunnya. Epidemiologi IMS saat ini berkembang sangat cepat karena berhubungan erat dengan berbagai faktor risiko sehingga meningkatkan insidensi dan prevalensi. Infeksi menular seksual menimbulkan beban besar terhadap morbiditas dan mortalitas di negara berkembang (1)

Dinamika transmisi IMS pada area geografis tertentu, IMS secara patogen dapat ditularkan diantara atau dari individu berisiko tinggi dengan angka infeksi yang tinggi dan sering berganti pasangan seksual (kelompok inti atau core group). Perkembangan epidemik IMS menurut Kementerian Kesehatan Republik Indonesia tahun 2013, dapat menyebar dari kelompok inti kepada populasi pelanggan (populasi antara atau bridging population) yang menjadi perantara penting lintas seksual antara kelompok inti dan populasi umum Kemenkes RI tahun 2013. Salah satu kelompok yang berisiko menularkan IMS adalah waria yang berganti-ganti pasangan seksual tanpa menggunakan kondom. Mobilitas waria yang tinggi, berpindah-pindah tempat dan tetap melakukan kontak seksual yang tidak aman sangat rentan menularkan pemyakit infeksi seksual.

Salah satu penyebab terjadinya penularan IMS adalah pengetahuan dan sikap waria mengenai perilaku berisiko. Pengetahuan yang minim mengenai penularan penyakit menular seksual sehingga tidak menggunakan kondom saat bertransaksi seksual kecuali atas permintaan mitra seksualnya. Penelitian Sumariyah mengenai Perilaku Seksual Waria Pekerja Seks dalam Pencegahan Penyakit Menular Seksual (PMS) di Kota Pekalongan mengungkapkan bahwa banyak waria yang enggan menggunakan kondom, dengan alasan mengurangi kenyamanan dalam berhubungan. Pengetahuan yang minim mengenai kejadian IMS berdampak pada sikap waria mengenai penularan dan penyebaran IMS yang semakin meluas (2).

Di Kota Makassar, terdapat banyak kelompok-kelompok waria dan aktif melakukan hubungan seksual berisiko yang berpotensi menyebabkan IMS yang merupakan pintu masuk penyakit HIV/AIDS. Penyakit ini mengalami peningkatan setiap tahunnya, yakin tahun 2015 tercatat sebanyak 665 HIV positif baru, tahun 2016 meningkat menjadi 773, lalu 2017 sebanyak 1038

1,2 Universitas Muslim Indonesia 
HIV baru dan hingga Juni 2018 terdapat 354 orang yang terinfeksi HIV baru. Sementara itu, waria merupakan kelompok populasi kunci yang sangat rentan terinfeksi dan menginfeksi karena hubungan seksual yang berganti-ganti pasangan. Hal ini disebabkan karena pengetahuan waria yang minim mengenai kesehatan reproduksi dan seksual. Tujuan penelitian ini utnuk Menganalisis Efektivitas Penggunaan Media Video dan Leaflet Terhadap Pengetahuan dan Sikap Waria Mengenai Infeksi Menular Seksual (IMS) di Kota Makassar.

Minimnya pengetahuan waria disebabkan karena kurangnya paparan informasi yang didapatkan terkait penularan IMS. Berkaitan dengan hal tersebut, sehingga sangat penting untuk diberikan informasi untuk merubah pengetahuan, sikap agar dapat mengadopsi perilaku yang positif. Untuk itu, diperlukan adanya media penyampai pesan yang sebagai cara untuk meberikan informasi kesehatan reproduksi dan seksual kepada waria. Salah satu media yang dapat mengedukasi waria adalah melalui video. Video yang menarik dapat efektif merubah pengetahuan dan sikap karena mengandung audio dan visual serta mengandung efek tertentu terhadap pesan yang disampaikan.

Berdasarkan data sekunder yang telah didapatkan dari dinas kesehatan Kota Makassar mengenai perkembangan jumlah IMS, didapatkan pula informasi awal dari waria bahwa penyakit seksual yang diketahui hanya HIV/AIDS dan sifilis, untuk pencegahan, tanda-tanda dan pengobatannya, waria belum begitu mengetahuinya. Begitupun dengan perilaku berisiko seperti berganti-ganti pasangan seksual dan kecendurgnan mengikuti permintaan pasangan seksualnya jika ada yang tidak mau memakai kondom, hal ini menambah rentan terular IMS pada waria di Kota Makassar.

Waria merupakan populasi kunci terbanyak di Kota Makassar dan merupakan salajh satu kelompok yang aktif melakukan hub ungan seksual yang berisiko, sehingga sangat penting diberikan informasi dengan menggunakan media yang menarik dan mudah dipahami agar terjadi adopsi perilaku.

\section{Metode}

Penelitian ini menggunakan penelitian Kuantitatif dengan pendekatan quasi eksperimen. Desain penelitian ini menggunakan rancangan pre experiment (one group pretest posttest). . Populasi pada penelitian ini adalah Waria di Wilayah Kecamatan Mamajang Kota Makassar sebanyak 84 orang. Adapun metode sampel yang digunakan dalam penelitian ini yaitu metode Porposive Sampling dengan kriteria adalah waria yang bersedia untuk diteliti, mulai usia 17-24 tahun, tingkat pendidikan minimal SMP sehingga didapatkan sampel sebanyak 30 waria. Tahapan Penelitian, Tahap I Melakukan penjaringan waria sebagai sampel penelitian sesuai dengan criteria, Tahap II Data primer dikumpulkan untuk menilai pengetahuan dan sikap waria tentang Infeksi Menular Seksual diperoleh dengan menggunakan kuesioner, Tahap III. Intervensi yang diakukan yaitu berupa pemberian informasi melalui media audio dan visual tentang Infeksi Menular Seksual, Tahap IV Setelah 1 bulan dilakukan intervensi maka pengukuran kembali pengetahuan dan sikap waria dengan menggunakan kuesioner yang sama pada saat sebelum intervensi. Pengumpulan Data dilakukan dengan data primer diperoleh melalui hasil pengisian angket oleh responden dengan cara membagikan kuesioner yang telah disusun sebelumnya, yang bersisi pertanyaan mengenai Infeksi Menular Seksual. Sedangkan data sekunder diperoleh dari Yayasan Gaya Celebes yang menangani Gay, Waria dan Laki-Laki Seks Laki-laki (GWL). Pengolahan data dilakukan dengan menggunakan computer melalui tahap Editing, Coding, Entri, dan Cleaning. Analisis Data digunakan Analisis Univariat, dan Analisis Bivariat.

\section{Hasil Penelitian}

Penelitian ini dilaksanakan di yayasan gaya Celebes (YGC) Kota Makassar pada bulan Juni sampai Juli. Sampel dalam penelitian ini meliputi seluruh anggota YGC dan Waria yang berada di Kecamatan Mamajang berusia 17-24 yang hadir dan memenuhi kriteria.

Hasil penelitian ini diperoleh melalui data primer yaitu dengan menggunakan kuesioner yang memuat 25 pertanyaan terdiri dari 15 pertanyaan untuk mengukur pengetahuan dan 10 
pertanyaan untuk mengukur sikap. Kuesioner disebar sebanyak 60 kuesioner sesuai dengan jumlah sampel yang memenuhi criteria untuk Pre dan posttest. Hasil penelitian ini diuraikan dalam table Univariat dan Bivariat sebagai berikut:

\section{Tabel 1}

Distribusi Frekuensi Berdasarkan Umur Tahun 2019

\begin{tabular}{lll}
\hline Kelompok Umur & $\mathrm{N}$ & $\%$ \\
\hline 17 Tahun & 1 & 3,3 \\
18 Tahun & 1 & 3,3 \\
19 Tahun & 1 & 3,3 \\
20 Tahun & 3 & 10,0 \\
21 Tahun & 6 & 20,0 \\
22 Tahun & 5 & 16,7 \\
23 Tahun & 9 & 30,0 \\
24 Tahun & 4 & 13,3 \\
\hline Jumlah & 30 & 100
\end{tabular}

Sumber : Data Primer 2019

Berdasarkan tabel 1 menunjukkan bahwa dari 30 orang yang dijadikan sebagai sampel, Umur tersebut memasuki masa remaja akhir dimana menurut Depkes RI peralihan dari remaja menjadi dewasa di ikuti oleh perkembangan hormon pada seseorang yang mengubahnya menjadi berbeda secara fisik yang lebih matang.

\section{Tabel 2}

Distribusi Frekuensi Berdasarkan Pretest Pengetahuan IMS Tahun 2019

\begin{tabular}{lll}
\hline Pretest & N & $\%$ \\
Pengetahuan IMS & & \\
\hline Kurang & 12 & 40,0 \\
Baik & 18 & 60,0 \\
\hline Jumlah & 30 & 100,0 \\
\hline
\end{tabular}

Sumber : Data Primer 2019

Berdasarkan tabel 5.5 menunjukkan bahwa dari 30 orang yang dijadikan sebagai sampel, yang berpengetahuan kurang sebanyak 12 orang $(40,0 \%)$ dan yang berpengetahuan baik sebanyak 18 orang $(60,0 \%)$.

\section{Tabel 3}

Distribusi Frekuensi Berdasarkan Postest Pengetahuan IMS Tahun 2019

\begin{tabular}{lll}
\hline Postest & $\mathrm{N}$ & $\%$ \\
Pengetahuan IMS & & \\
\hline Kurang & 9 & 30,0 \\
Baik & 21 & 70,0 \\
\hline Jumlah & 30 & 100,0 \\
\hline
\end{tabular}

Sumber : Data Primer 2019

Berdasarkan tabel 5.6 menunjukkan bahwa dari 30 orang yang dijadikan sebagai sampel, yang berpengetahuan kurang sebanyak 9 orang $(30,0 \%)$ dan yang berpengetahuan baik sebanyak 21 orang $(70,0 \%)$.

\section{Tabel 4}

Tabel Uji Paired Sampel T Test Tahun 2019

\begin{tabular}{llll}
\hline Kelompok & Mean & Korelasi & Sig \\
\hline Pretest Pengetahuan & 51,10 & 0,468 & 0,105 \\
Posttest Pengetahuan & 57,20 & & \\
\hline
\end{tabular}

Sumber : Data Primer 2019 
Berdasarkan tabel 5.11 menunjukkan bahwa dari 30 orang yang dijadikan sebagai sampel, kelompok pretest sikap dengan nilai sig. 0,005 (Tidak normal) sedangkan postest 0,007 (Normal).

Berdasarkan hasil penelitian dari 30 orang yang di jadikan sampel diketahui bahwa umur responden dengan jumlah paling banyak adalah 20-24 tahun sebanyak 35 orang, sedangkan yang terendah yaitu $<20$ tahun berjumlah 6 orang $(14,6 \%)$.

Hasil penelitian ini menunjukkan bahwa responden berada pada rentang 17-24 tahun memasuki usia remaja akhir. Remaja tahap ini mendekati masa dewasa yang ditandai dengan minat yang semakin mantap terhadap fungsi-fungsi, egonya mencari kesempat-an bersatu dengan dengan orang lain untuk mendapatkan pengalaman baru, terbentuk indentitas yang tidak berubah lagi. Remaja mulai tampak bebas ingin mencari identitas diri, adanya keingin ketertarikan pada sejenis, ada perasaan cinta, kemampuan berpikir secara abstrak berkembang berkhayal mengenai hal-hal yang berkaitan dengan seksual. masa ini remaja penuh gejolak, termasuk masa interaksi dengan kawan sejenis. Menurut seorang psikolog Elisabeth Hurlock usia remaja merupakan usia pencarian jati diri dengan karakteristik khasnya suka mencoba halhal yang baru dan melakukan sesuatu yang menantang (3)

\section{Diskusi}

Tingkat Pengetahuan Tentang infeksi menular seksual pada Waria Pretest dan Posttest dengan intervensi video Mengenai IMS

Pengetahuan merupakan domain yang sangat penting untuk terbentuknya perilaku. Pengetahuan manusia dapat dikelompokkan dalam berbagai macam sesuai dengan metode dan pendekatan yang mau digunakan. Penelitian ini menggunakan intervensi video yang diberikan pada waria di kecamatan Mamajang kota Makassar, sebelum melakukan intevensi dengan video terlebih dahulu dilakukan pengisian kuesioner dengan 15 butir petanyaan tentang pengetahuan, 10 butir pertanyaan tentang sikap. Setelah itu menstimulus waria untuk mengorientasikan suatu permasalahan tentang infeksi menular seksual.

Setelah mendapatkan data dari pretest dilanjutkan dengan memberikan edukasi melalui video berdurasi kurang lebih 15 menit dengan 2x pemutaran berisi tentang materi infeksi menular seksual, video ini ditunjang dengan animasi dan gambar yang menarik, penjelasan yang singkat dan tentunya menarik perhatian pembacanya, selanjutnya memberikan kesempatan kepada Waria untuk memberikan respon atas penanyangan video tersebut.

Hasil penelitian menunjukkan bahwa sebelum diberikan promosi kesehatan, pengetahuan kurang waria mengenai IMS adalah $40 \%$ dan pengetahuan baik sebanyak $60 \%$. Adanya waria yang memiliki pengetahuan kurang karena belum mendapatkan informasi yang jelas mengenai IMS dan waria tersebut tidak dalam naungan komunitas.. Setelah di lakukan pretest di diberikan edukasi yang dilanjutkan dengan diskusi atau tanya jawab. Berdasarkan pertanyaan dari beberapa waria dapat disimpulkan bahwa mereka mengetahui penyakit menular seksual namun jenis HIV/Aids dan sipilis saja, namun gejala termasuk penangannya masih awam.

Hasil posttest Setelah diberikan edukasi melalui video, didapatkan bahwa waria dengan pengetahuan kurang sebanyak 30\% dan pengetahuan baik sebanyak 70\%. Berdasarkan hasil tersebut di ketahui bahwa dari 30 waria terdapat perubahan pengetahuan yaitu pengetahuan Waria yang meningkat sebanyak $10 \%$. menunjukan bahwa terjadi peningkatan pengetahuan setelah di berikan intervensi melalui pemutaran film pendek berdurasi 15 menit pada Waria. Peningkatan ini tidak lepas dari antusias Waria pada saat pemutaran film dan interaksi saat diskusi dan memahami gambar gambar serta penjelasan yang di tampilkan di dalam video.

Adanya peningkatan pengetahuan pada Waria selain pemberian edukasi berupa video mengenai IMS, hal lain karena media yang digunakan merupakn hal yang baru diterimanya, meskipun sebelumnya pernah mendapatkan informasi namun hanya sekilas dan bersifat umum. usia responden 17-24 tahun sudah bisa menerima dan menyeleksi pesan yang diterima serta 
dapat menyimak mengenai materi yang didapatkan. Latar belakang pendidikan juga mempengaruhi adanya pengetahuan yang lebih baik, responden dalam penelitian ini ada yang tamat SMA dan Mahasiswa, begitupun dengan pekerjaanya yang bervariasi dan memungkinkan untuk berinteraksi dengan benyak orang sehingga memberikan pengalaman yang lebih banyak dibandingkan bagi yang berpendidikan minim dan tidak bekerja.

Peningkatan pengetahuan pada waria karena adanya stimulus yang diterima dengan baik mengenai infeksi menular seksual (IMS) yang diberikan melalui media video yang lebih mudah dipahami dan lebih menarik perhatian sehingga akan tersimpan dalam memori. Sadiman mengungkapkan bahwa video dapat memberikan stimulus terhadap pandangan dan pendengaran dengan memegang prinisp psikomotor, behavioristik dan kognitif sehingga seseorang bisa menerima informasi melalui indera pengelihatan dan pendengaran, sehingga informasi yang disampaikan dapat diterima secara maksimalPengetahuan seseorang bersumber dari penginderaan mereka, yakni pengelihatan, rasa, raba dan pendengaran. Salah satu faktor yang paling mempengaruhi pengetahuan seseorang adalah indera pengelihatan dan pendegaran, dimana salah salah satu media penyalur tersebut adalah video (4)

Tingkatan pengetahuan waria sebelum edukasi berada pada tahap tahu dan memahami namun ada yang tidak mengaplikasikannya seperti penggunaan kondom lebih menyerahkan kepada keinginan pasangan padahal waria cenderung tidak memiliki pasangan menetap. Kebiasaan tidak menggunakan kondom dan berganti ganti pasangan sangat berisiko akan terkena penyakit HIV AIDS. Hasil tersebut sejalan dengan yang dilakukan oleh (5)

Faulina, yang mengungkapkan bahwa waria tidak selalu menggunakan kondom pada saat berhubungan seksual dengan pelanggan. Alasannya adalah karena pelanggan tidak nyaman saat melakukan hubungan seks dengan memakai kondom. HIV ada karena beberapa penyakit menular seksual sebelumnya yang menjadi pintu masuk HIV seperti clamidya, herpes, sifilis, hepatitis. Waria sangat berisiko terinfeksi penyakit menular seksual karena hubungan seksual melalui anus yang dapat menimbulkan perlukaan yang terjadi saat berhubungan seksual. Hal ini sejalan dengan penelitian Suwandani tahun 2015 mengenai pengetahuan dan sikap berisiko waria dengan kejadian infeksi menular seksual (ims) pada waria di sidoarjo, mengungkapkan bahwa Dampak perilaku seks beresiko, terlihat pada kejadian HIV dan riwayat infeksi menular seksual yang cukup tinggi, terutama pada waria. Seperti diketahui, adanya IMS dapat mempermudahkan penularan HIV (5).

Setelah di analisis terjadi tingkatan pengetahuan yang sebelumnya hanya tahu dan memahami. Setelah di berikan edukasi waria sudah bisa mengaplikasikan bahwa pentingnya menggunakan kondom dan menganalisis kejadian bahwa HIV AIDS itu di awali dengan penyakit penyakit infeksi menular seksual (IMS) sebelumnya seperti clamidya, herpes, sifilis, hepatitis.

Pengetahuan waria yang menetap atau tidak mengalami perubahan meskipun telah diberikan edukasi disebabkan pada saat pemutaran video karena adanya istilah-istilah baru mengenai IMS seperti penyakit Gonorrhea, Clamidyia, herpes kelamin, responden pada umunya hanya mengetahui jenis IMS seperti Siphilis dan HIV/AIDS, selain itu responden tersebut bukan merupakan bagian dari komunitas yang membina Gay, Waria dan LSL di Kota Makassar. Selain itu, latar belakang pendidikan waria yang minim (SD dan SMP tidak Tamat) juga mempengaruhi penerimaan informasi apalagi video hanya diberikan 1 kali pemutaran dengan durasi selama 15 menit. Hal lain yg mempengaruhi pengetahuan waria yaitu jarak antara pemberian pretest dan posttest sekitar kurang lebih 2 minggu setelah di adakannya intervensi pemutaran video. Ini menyebabkan menurunnya daya ingat pada waria apalagi mereka ada yang bekerja di salon yang perhatian dan energinya terkuras selama bekerja.

Berdasarkan hasil uji Paired T testdidapatkan nilai 0,105 yang berarti tidak ada hubungan antara edukasi melalui video terhadap pengetahuan waria. Hal ini dapat disebabkan karena responden bingung dengan adanya istilah-istilah yang baru dan tidak familiar bagi mereka terkait Infeksi menular seksual, selain itu sampel dalam penelitian ini hanya 30 orang sehingga bisa sajamenghasilkan hasil uji yang tidak signifikan. 
Andi Asrina, R. Sudirman: Efektivitas penggunaan media video learning multimedia ( $\mathrm{vlm}$ ) terhadap pengetahuan infeksi menular seksual (IMS) (studi pada waria di kota Makassar). Jurnal Kesehatan. Vol 13 (2) 2020

\section{Kesimpulan}

Berdasarkan hasil penelitian menegenai Efektivitas Penggunaan Media Video Learning Multimedia (VLM) Terhadap Pengetahuan Infeksi Menular Seksual (IMS) pada Waria di Kota Makassar, dapayt disimpulkan bahwa tidak ada pengaruh secara signifikan antara penggunaan video menegnai IMS terhadap pengetahuan warian dengan hasil uji Paired T Test dengan nilai 0,015 .

\section{Daftar Pustaka}

1. Masni. Faktor risiko kejadian infeksi menular seksual di puskesmas kalumata kota Ternate. 2016.

2. Sumariyah. Perilaku Seksual Waria Pekerja Seks dalam Pencegahan Penyakit Menular Seksual (PMS) di Kota Pekalongan. 2012

3. Hurlock, E. B. Psikologi Perkembangan, Suatu Pendekatan Sepanjang Rentang Kehidupan (terjemahan). Jakarta: Erlangga. 2012.

4. Sadiman, dkk. Media Pendidikan, Pengertian, Pengembangan, dan. Pemanfaatannya. Jakarta: PT. Raja Grafindo Persada. Azhar Arsyad. 2012.

5. Suwandani. Pengetahuan dan sikap berisiko waria dengan kejadian infeksi menular seksual (ims) pada waria di sidoarjo. 2015. 